\title{
Frictional characteristics of diamond like carbon and tungsten carbide/carbon coated high carbon high chromium steel against carbon in dry sliding conformal contact for mechanical seals
}

\author{
S. ShankAR ${ }^{\mathrm{a}}$ AND P. KRIShna Kumar \\ Department of Mechatronics Engineering, Kongu Engineering College, Erode, Tamilnadu 638052, India
}

Received 4 May 2015, Accepted 10 June 2016

\begin{abstract}
The present work investigates the friction characteristics of high carbon high chromium steel $(\mathrm{HCHCr})$ stationary seal in contact with resin impregnated carbon rotating seal without any interfacial lubricant. An experimental setup was designed and fabricated to study the frictional characteristics of the seal for varying normal load and at a constant speed. The reliability and frictional performance had been improved further by providing DLC (diamond like carbon) and WC/C (tungsten carbide/carbon) coating over the substrate HCHCr D2 steel surface. Compared with the conventional stainless steel (316 SS) mechanical seals, uncoated HCHCr D2 steel had shown better frictional characteristics. Also further deposition of DLC and WC/C film on HCHCr D2 steel had shown significant improvement in the frictional torque, frictional coefficient and face temperature rise. The high hardness and low surface roughness of DLC and WC/C coated seal resulted in low and stable friction coefficient in the range of 0.04-0.05 without any measurable wear.
\end{abstract}

Key words: Mechanical seal / friction / diamond like carbon / HCHCr steel / 316 stainless steel

\section{Introduction}

Mechanical seals are the sealing device for any rotating equipment, which prevents the leakages of liquids, gases or any other hazardous process fluids through the clearance between the housing case and the rotating shaft of the pump [1-3]. It is specially designed to be used in centrifugal pumps, mixers, compressors, boiler-feed pumps, agitators and rotary unions. It incorporates various components such as rotating ring (softer material), stationary ring (harder material), and a spring, which ensures the actuation force for proper mating of ring at specific pressure. Over the past two decades, pioneering studies have been made in improving the bulk properties [4-6] and surface sensitive properties of the mechanical seals to enhance its performance and durability. In general, researchers had tried two approaches using surface engineering concepts $[7,8]$. Surface texturing techniques were mainly utilized to improve the performance characteristics such as vibro rolling, undulated surfaces, reactive ion etching, abrasive jet machining, lithography and anisotropic etching. Overall, laser surface texturing had proved to be the most advanced and effective technique which improves the load bearing capacity, wear resistance, coefficient of

\footnotetext{
${ }^{a}$ Corresponding author: shankariitm@gmail.com
}

friction of the mechanical seals by producing number of micro-dimples on the sliding surface [9-13]. Also, several studies reported with providing hard coatings over mechanical seals using physical vapor deposition, chemical vapor deposition on the sliding surface to prevent tribological related failures. In low friction CVD coatings various diamond films such as nanocrystalline diamond (NCD) films and ultrananocrystalline (UNCD) diamond films were coated to enhance the tribological properties of mechanical seals $[8,14,15]$, whereas in PVD coatings, diamond like carbon (DLC) had proven to be very efficient $[16,17]$. It basically consists of a mixture of diamond $\left(s p^{3}\right)$ and graphite $\left(s p^{2}\right)$, where its relative amount of these two phases will determine the mechanical and tribological properties of the coating.

In current practice, several different types of DLC coatings [18], such as pure DLC, metal-doped DLC, and carbide-doped DLC, were utilized. Among which, tungsten carbide/carbon (WC/C) coating (a-C:H:W) [19] and pure DLC coating (a-C:H) were found to be more potential for sliding/rotating tribological surfaces. These coatings provide good wear resistance, low frictional coefficients, and high load bearing capacity. These coatings also proved to be an efficient option in improving the tribological properties for various other mechanical components 
such as gears, ball bearings, punching and forming tools, cutting tools and so on [20]. To the best of our knowledge, as far as the application of mechanical seals is considered, there had been more research work carried out in the surface texturing of the tribological seal surfaces using the laser surface texturing technique and development of diamond films (NCD and UNCD) on the sliding surface of the mechanical seals substrates such as silicon nitride $\left(\mathrm{Si}_{3} \mathrm{~N}_{4}\right)$, silicon carbide $(\mathrm{SiC})$. But commercialization of these techniques is really a time consuming and uneconomical. Considering the application of mechanical seals, there are many factors such as sliding velocity, normal load, seal face temperature, seal face material, pairing of stationary and rotating seal faces, which decide its frictional characteristics.

In the present work, high carbon high chromium steel (HCHCr D2 steel) is employed as stationary seal and resin impregnated carbon known for its superior wear resistance, anti-friction properties and corrosion properties, is employed as rotating seal. In addition to that, low friction PVD coatings of tungsten carbide/carbon (WC/C) coating (a-C:H:W) and pure DLC coating (a-C:H) were deposited over HCHCr D2 steel stationary ring to improve its sliding properties, coefficient of friction, load bearing capacity, wear resistance and corrosion resistance. Also in most cases, the effect of hard coatings and their tribological behavior have been investigated by using a three ballon-rod tester, pin-on-ring tester, roller tester, four ball tester, ball on disc and dry ball-on-flat reciprocating tribometers and so on. But in this present work, a specially designed mechanical seal test rig had been utilized to study the frictional characteristics of the mechanical seal. Also in specific seal applications, like agitators and boiler feed pumps an abrupt change in speed and load occurs, resulting in abnormal friction and unexpected wear [21]. So, in this work the seals were tested for various loads ranging from $75 \mathrm{~N}$ to $350 \mathrm{~N}$ at a constant speed.

\section{Experimental methods}

\subsection{Material and specimen preparation}

$\mathrm{HCHCr}$ D2 steel is an air hardened high carbon high chromium steel, which is known for its high hardness, high strength, high wear resistant, easy to process, easily available and low cost [22]. HCHCr D2 steel round bar of diameter $50 \mathrm{~mm}$ is machined using $\mathrm{CNC}$ turning center to a hollow ring of $\varnothing 43 \times \varnothing 33 \times 8 \mathrm{~mm}($ od $\times$ id $\times$ thickness $)$. The HCHCr D2 steel stationary ring was found to have the hardness of 57HRC measured using Mitutoyo Rockwell hardness testing machine HR-210MR. The chemical compositions of HCHCr D2 steel is reported in Table 1. Whereas, stainless steel (316 SS) seal of $\varnothing 43 \times \varnothing 33 \times 8 \mathrm{~mm}$ (od $\times$ id $\times$ thickness) was purchased commercially and utilized for testing.

In this study, resin impregnated carbon was used as a rotating ring, which is a widely used seal face material because of its superior wear resistance, anti-friction properties and corrosion properties [23]. The rotating
Table 1. Typical chemical composition of HCHCr D2 steel.

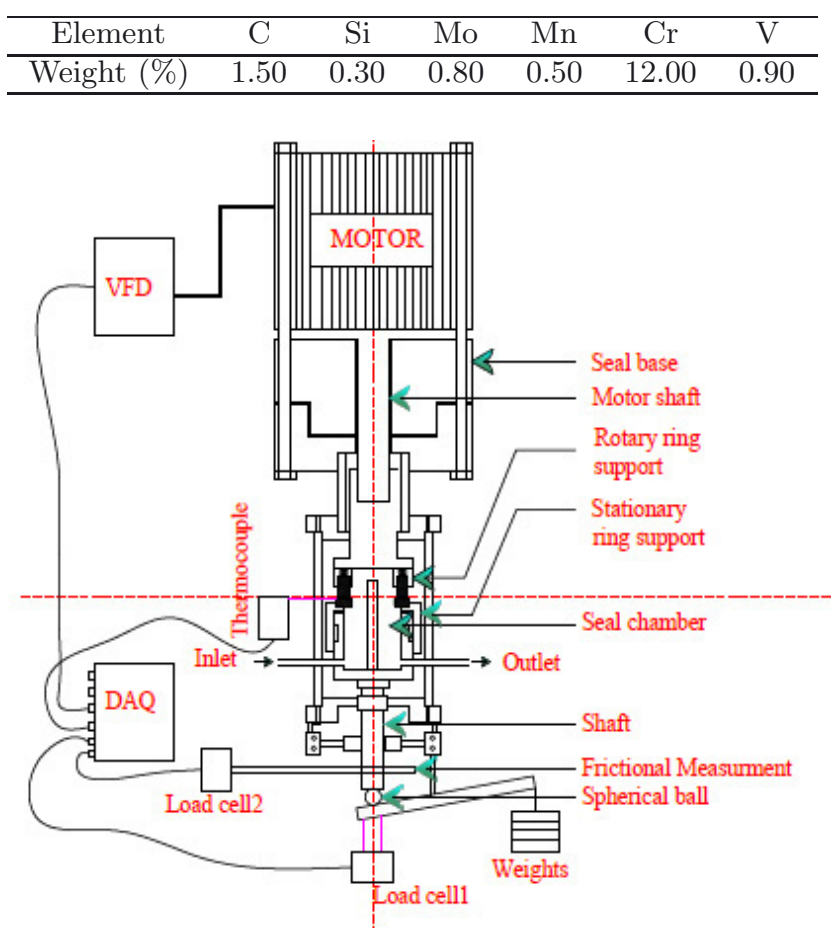

Fig. 1. Schematic diagram of Mechanical seal test rig.

ring was purchased commercially with the dimensions of $\varnothing 45 \times \varnothing 38 \mathrm{~mm}($ od $\times$ id $)$.

\subsection{Mechanical seal test rig}

\subsubsection{Description of equipment}

The designed seal test rig shown in Figure 1, versatile equipment to conduct tests on multiple sizes of seals and also of different kinds of seal materials. The machine is equipped with a top holder, which can be hold the rotary seal, pressed over the hard surface on the stationary seal. The stationary seal locked in lower holder is made to press against rotary seal rotated by spindle; proper spring pressure between rings is maintained by placing dead weights on the designed pan at the end of lever arrangement to ensure full engagement. The spindle is rotated by a motor with belt drive, the speed of motor is controlled by a variable frequency drive to provide uniform torque at all speeds [21]. Resistance temperature detector (RTD) sensors is mounted on the side of lower holder with the tip touching the outer diameter of stationary seal are used to measure the temperature of the outer diameter of the stationary seal. The proximity sensor is employed to measure the spindle speed. The mechanical seal test rig, incorporated with the data acquisition card (I-DAS) does the sampling of signals obtained through the above mentioned sensors, which can be recorded in the computer. The data acquisition card was controlled by the WINDUCOM software (Ducom Instruments). 
Table 2. Mechanical properties of different selected specimens.

\begin{tabular}{ccccc}
\hline Properties & WC/C coated & DLC coated & HCHCr D2 steel & 316 Stainless steel \\
\hline Thickness $(\mu \mathrm{m})$ approx. & $1.85 \pm 0.012$ & $1.79 \pm 0.014$ & - & - \\
Surface roughness, $R a(\mu \mathrm{m})$ & $0.39 \pm 0.12$ & $0.42 \pm 0.015$ & $0.37 \pm 0.011$ & $0.21 \pm 0.022$ \\
Microhardness, $\mathrm{HV}_{50 \mathrm{~g}}$ & $1500 \pm 155$ & $2000 \pm 140$ & $660 \pm 90$ & $190 \pm 85$ \\
\hline
\end{tabular}

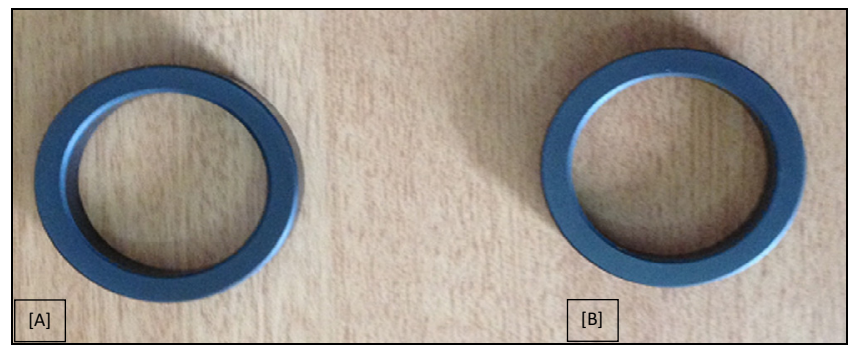

Fig. 2. (A) WC/C coated seal ring (B) DLC coated seal ring.

\subsection{Film deposition and characterization}

$\mathrm{WC} / \mathrm{C}$ and pure DLC coatings were produced on HCHCr D2 steel using DC magnetron sputtering process [24]. Before the insertion of stationary seal into the vacuum chamber, all the substrate were cleaned and dried. Each category of coatings, the deposition sequence starts with DC magnetron sputtering of chromium layer to promote adhesion. The vacuum chamber was then evacuated to a pressure less than $1 \times 10^{-3} \mathrm{~Pa}$. The WC/C phase was deposited using the target material $\mathrm{WC} / \mathrm{Ni}$ (WC $93 \mathrm{wt} \%$ and Ni $7 \mathrm{wt} \%$ ) with argon as sputtering gas, and the carbon phase was grown from plasma containing acetylene $\left(\mathrm{C}_{2} \mathrm{H}_{2}\right)$ and argon. The major ingredient of the DLC coating was amorphous carbon $(\mathrm{a}-\mathrm{C})$. In both coatings, the $\mathrm{HCHCr}$ D2 steel was maintained at the temperature of about $210{ }^{\circ} \mathrm{C}$ to $250{ }^{\circ} \mathrm{C}$. The coating thickness was appro $\times$ imately $2 \mu \mathrm{m}$, including the chromium layer of $0.1 \mu \mathrm{m}$ to $0.2 \mu \mathrm{m}$, with the processing time of $120 \mathrm{~min}$. The mechanical properties of the prepared stationary seals are presented in Table 2 . The surface roughness of the specimens was measured using the Mitutoyo SJ-410 roughness tester before and after conducting the test. The entire coated specimen exhibited higher Ra value than the uncoated specimen, which had a Ra of approximately $0.37 \mu \mathrm{m}$.Images of coated mechanical seals were shown in Figure 2.

\subsection{Testing procedure}

The entire tests were carried out on a mechanical seal test rig, shown in Figure 1, under dry running condition with atmosphere air at room temperature $-31{ }^{\circ} \mathrm{C}$ and humidity $55 \%$. The stationary ring was mounted in fluid chamber that allows the self-alignment of the ring and also permits axial loading of the stationary ring against the upper rotating ring. Initial load of $75 \mathrm{~N}$ was applied at the end of the lever for the full engagement of the stationary and rotary ring. Each test includes a $3600 \mathrm{~s}$ running-in period with a constant speed of $1500 \mathrm{rpm}$ for six loading conditions. After running-in, the load between the rings was varied from $75 \mathrm{~N}$ to $350 \mathrm{~N}$ (in a step of $75 \mathrm{~N}, 150 \mathrm{~N}, 200 \mathrm{~N}, 250 \mathrm{~N}, 300 \mathrm{~N}, 350 \mathrm{~N}$ ) [25]. For each loading, the running-in period was $600 \mathrm{~s}$. After each loading conditions, the test was halted for $5 \mathrm{~min}$. The seal face temperature; friction torque and coefficient of friction were recorded for every $1 \mathrm{~s}$ using WINDUCOM. The same procedure was repeated for all the stationary rings (316 SS, HCHCr D2 steel, WC/C coated, DLC coated). For the entire testing, resin impregnated carbon was used as rotary ring.

\section{Results and discussion}

\subsection{Friction coefficient}

Tests were repeated with three samples in each case and computed average friction coefficient was shown in Figure 3. For each loading conditions, the coefficient of friction attains its stable value approximately after $200 \mathrm{~s}$, which was found to be in agreement with the previous studies $[22,26]$. In case of HCHCr D2 steel uncoated seal, the friction at the initial stage (at $75 \mathrm{~N}$ load) of runningin was low and remains constant. The factors responsible for this low friction may be due to the presence of foreign materials on $\mathrm{HCHCr}$ D2 steel uncoated seal layer such as (i) moisture; (ii) oxides of metals and so on. So there may be little or minimum metallic contact at the junction and also the oxide film had lower shear strength resulting in low coefficient of friction. After initial running in, the surface layer breaks up and the clean surface comes in contact. At the same time, due to ploughing action shown in Figure 4, there may be a chance of inclusion of wear trapped particles [26] resulted with the increase in roughness, face temperature and friction force. These factors contribute with the increase in frictional coefficient values. After certain duration of running-in, the increase in roughness and other parameters reached the steady state value resulted in constant friction coefficient for the rest of the running-in period. The average of those friction coefficients $(\mu=0.061)$ has been calculated and shown in Figure 3 . The same phenomenon was found for all other loading conditions and their average friction coefficient was plotted in Figure 3. Whereas in 316 SS seals, the same phenomenon as mentioned above was found, except for the initial load of $75 \mathrm{~N}$ and the friction coefficient had reached a stable value of $\mu=0.097$. The average coefficient of friction for each loading condition was given in Figure 3.

In case of DLC coated seal, the friction coefficient attained a lower value of 0.082 at initial load of $75 \mathrm{~N}$. 


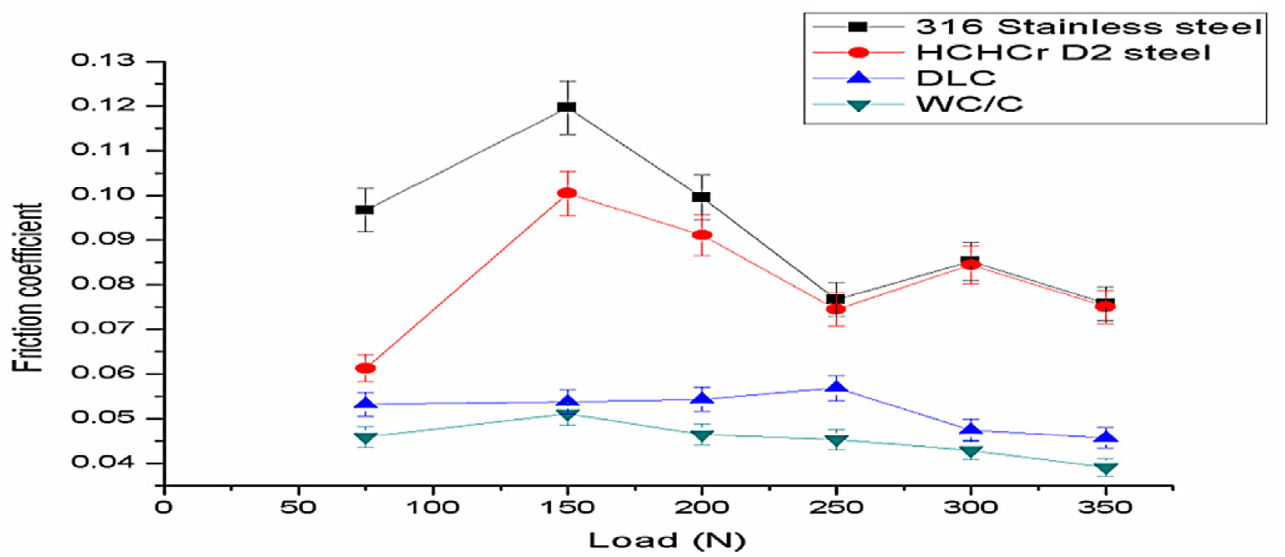

Fig. 3. Variation of frictional coefficient for different seal.

After that, the friction coefficient was found to be in fluctuating trend and increased to higher friction coefficient $(\mu=0.105)$. This may be due to the detachment of wear debris, as a result of sliding between two mating surfaces. This wear debris acted as an abrasive particle trapped between the two mating surfaces [20,27], which increasing the sliding resistance as well as roughness, face temperature and friction force of the mating surfaces. After this stage i.e. approximately after $200 \mathrm{~s}$, the friction coefficient attains a stable value $(\mu=0.051)$. This may be due to the formation of tribofilm as a consequence of sliding of two mating surfaces [28], which is adhered above the DLC coated seals, which had an significant effect in reducing the friction coefficient. The average of those friction coefficients $(\mu=0.051)$ was given in Figure 3 . The same phenomenon was found for all other loading conditions, and their obtained average friction coefficient was shown in Figure 3.

In case of $\mathrm{WC} / \mathrm{C}$ coated seal, the same phenomenon was found, but the friction coefficient values were found to be lower than the HCHCr D2 steel uncoated and DLC coated seal. At initial load, after the start of running-in phase, it attained the lower friction coefficient value $(\mu=$ $0.062)$. There was no much increase in friction coefficient as like in the case of HCHCr D2 steel, 316 SS and DLC coated seals. This proved that the WC/C coated seal had higher wear resistance and also the detachment of wear debris was found to be less when compared with other two seals. After running-in, approximately after $200 \mathrm{~s}$, the friction coefficient attains a stable value $(\mu=0.044)$. The average of those friction coefficients $(\mu=0.045)$ was shown in Figure 3. The same phenomenon was found for all loading conditions which could be visible in Figure 3. The friction coefficient values of $\mathrm{WC} / \mathrm{C}$ coated seal and DLC coated seal was found to be agreement with the previous works [27].

These results suggested that the $\mathrm{WC} / \mathrm{C}$ coated seal exhibit higher wear resistance and lower frictional coefficient compared to DLC coated, HCHCr D2 steel and 316 SS seals. The average coefficient of friction of 316 SS was higher, whereas the $\mathrm{WC} / \mathrm{C}$ coated seal had the lowest value. It is evident from optical microscopy images as

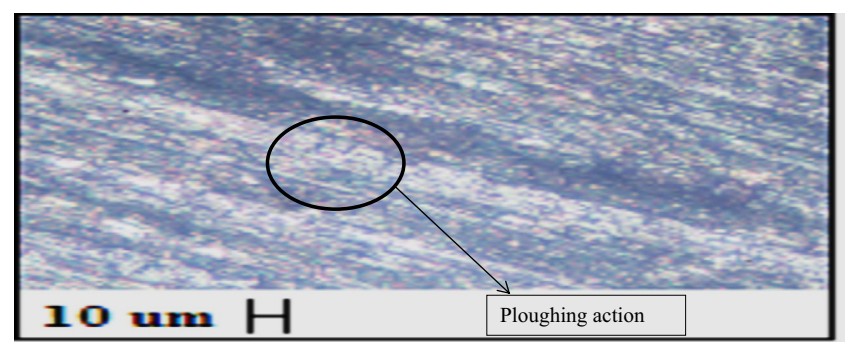

Fig. 4. Microstructure of the sliding path surface of $\mathrm{HCHCr}$ D2 steel seal after running-in test.

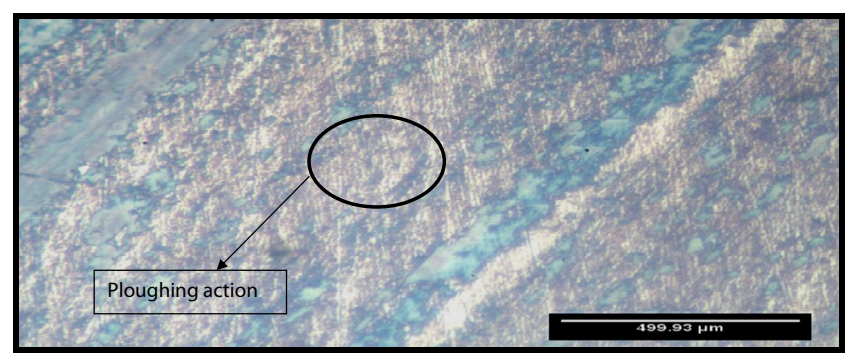

Fig. 5. Microstructure of the sliding path surface of 316 SS seal after running-in test .

shown in Figures 4-7, that there were no ploughing action in DLC coated and WC/C coated seals, as like in 316 SS and HCHCr D2 steel uncoated seal. After the experiments, DLC coated and WC/C optical microscopy images in Figures 6 and 7 shows minimal wear track as compared to uncoated seals. From the Table 3 , it is also evident, after the running-in test for $3600 \mathrm{~s}$, the $\mathrm{WC} / \mathrm{C}$ coated seal exhibited lower surface roughness $(R a=0.42 \mu \mathrm{m})$, in compare with the DLC coated $(R a=0.47 \mu \mathrm{m})$, HCHCr D2 steel $(R a=0.89 \mu \mathrm{m})$ and $316 \mathrm{SS}(R a=0.88 \mu \mathrm{m})$. The results confirmed that the test carried out was not enough to cause any damage on the coating (Figs. 6 and 7) which may be due to the significant reduction of friction coefficient in $\mathrm{WC} / \mathrm{C}$ coated and DLC coated seals. 
Table 3. Variation of surface roughness.

\begin{tabular}{ccccc}
\hline Coating & WC/C & DLC & HCHCr D2 steel & 316 Stainless steel \\
\hline Before running-in test, & $0.39 \pm 0.012$ & $0.42 \pm 0.015$ & $0.37 \pm 0.011$ & $0.21 \pm 0.022$ \\
Surface roughness $R a(\mu \mathrm{m})$ & & & & \\
\hline After running-in test, & $0.42 \pm 0.011$ & $0.47 \pm 0.017$ & $0.89 \pm 0.021$ & $0.88 \pm 0.011$ \\
Surface roughness $R a(\mu \mathrm{m})$ & & & & \\
\hline
\end{tabular}
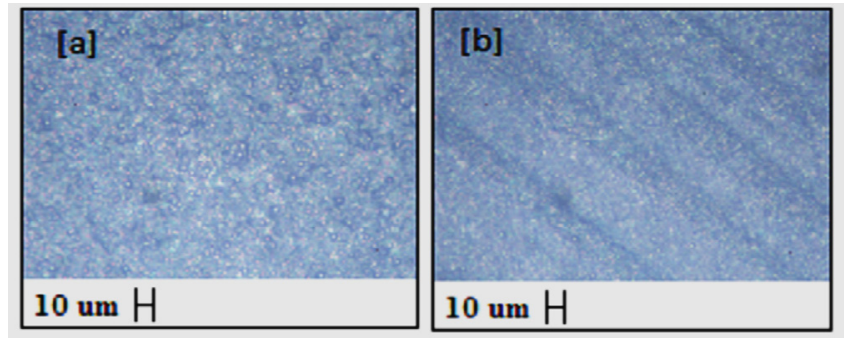

Fig. 6. Microstructure of the sliding path surface (a) DLC coated seal (b) WC/C coated seal before running-in test.
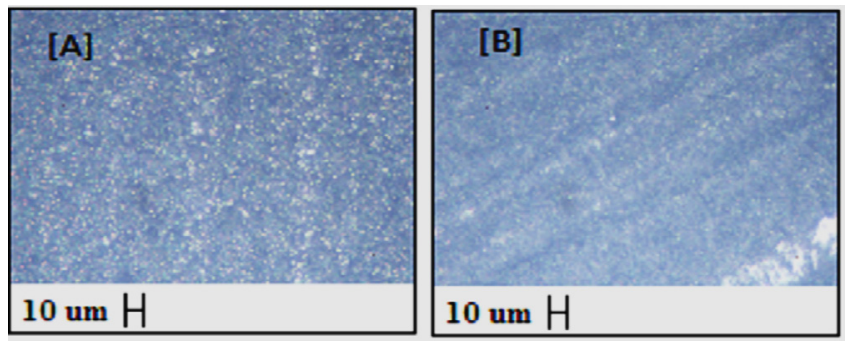

Fig. 7. Microstructure of the sliding path surface (A) DLC coated seal (B) WC/C coated seal after running-in test.

\subsection{Frictional torque}

Frictional torque has the direct influence over the frictional coefficient. In general, the increase in normal load (N) will increase the frictional torque which was confirmed from the Figure 8. As the normal load increases, the detachment of wear debris increases resulting in the increase in surface roughness, thereby the sliding resistance of the mating surface increases [29], eventually resulting in the increase of frictional force [21]. Figure 8 shows the variation of frictional torque of WC/C coated, DLC coated, HCHCr D2 steel and 316 SS seal for various normal loads. Among all the tested seals, WC/C coated seal exhibits the lower frictional torque compared to other category of seal material, which then increase the tribological behavior as well as the life span of the seal. 316 SS and uncoated HCHCr D2 steel shows more or less same behavior. The main drawback in using 316 SS seal was the adhesion issue in providing coating over the substrates. This problem can be eradicated while selecting $\mathrm{HCHCr}$ D2 as base substrate. Moreover the results from the coated samples had very low frictional torque compared to uncoated samples.

\subsection{Face temperature rise}

The face temperature rise is an important parameter which greatly influence the frictional characteristics and the life span of the mechanical seals [21]. In general, the face temperature rise was commonly seen in all four substrates of WC/C coated, DLC coated and HCHCr D2 steel, 316 SS seal. Figure 9 shows the face temperature rise of all samples, which was tested in the present case. However, in comparison with DLC coated, HCHCr D2 steel and $316 \mathrm{SS}$ seal, the $\mathrm{WC} / \mathrm{C}$ coated seal exhibited the lower face temperature rise. WC/C coated seal experiences the lowest temperature rise of about $86.05^{\circ} \mathrm{C}$, which was very low when compared with uncoated specimen which experienced $105.8^{\circ} \mathrm{C}$ temperature rise. It is also evident from the (Figs. $4-7$ ), there is no interference of ploughing action in $\mathrm{WC} / \mathrm{C}$ and DLC coated seals, as like in 316SS and $\mathrm{HCHCr}$ seal. Overall result suggested that the $\mathrm{WC} / \mathrm{C}$ coated seals improves the performance than the considered cases and the work also evident that $\mathrm{HCHCr}$ D2 steel might be a better alternative for 316 SS in future.

\section{Conclusions}

In the present work, the frictional characteristics of 316 SS, HCHCr D2 steel, PVD WC/C coated and DLC coated seals were evaluated using the designed experimental seal test rig. Among the four seal substrates, PVD DLC coated and WC/C coated seal exhibited the lower frictional coefficient, friction torque and face temperature rise. The WC/C coated seal also showed higher wear resistance to sliding wear compared to the other DLC coated seal and HCHCr D2 steel seal. The test was carried out for $3600 \mathrm{~s}$ resulted without any considerable damage to $\mathrm{WC} / \mathrm{C}$ coated substrate. These obtained results from PVD DLC and WC/C coated HCHCr D2 seal shows potential improvements in the friction characteristics and the seal life compared to 316 SS. Overall coated $\mathrm{HCHCr}$ D2 steel become a reliable mechanical seal for heavy load and high speed applications, also as a better alternate for 316 SS.

The present work highlights the running-in test of DLC and WC/C coated HCHCr seal under dry sliding conformal contact. Whereas the mechanical seal test rig is designed with the lubricating unit, so the study under lubricating conditions lies in our future work. Also, it investigates the initial starting frictional characteristics of pair involving $\mathrm{WC} / \mathrm{C}$ and DLC coated seal against carbon, so hence running-in test was carried out for $1 \mathrm{~h}$. The 


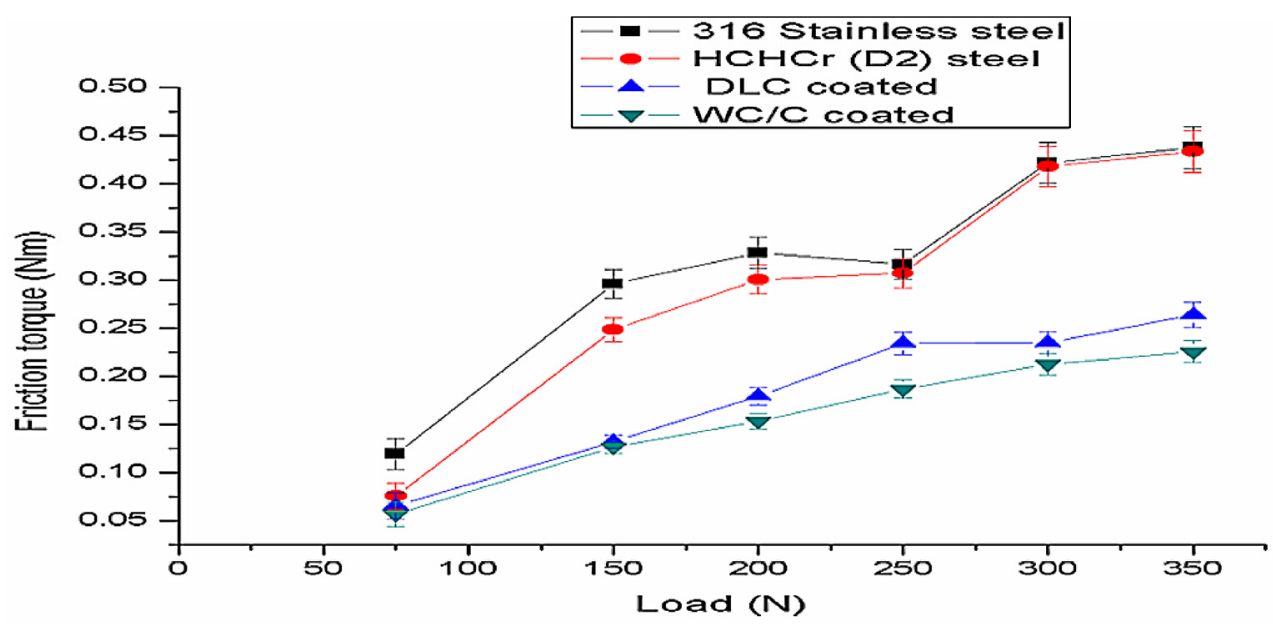

Fig. 8. Variation of friction torque for different seals.

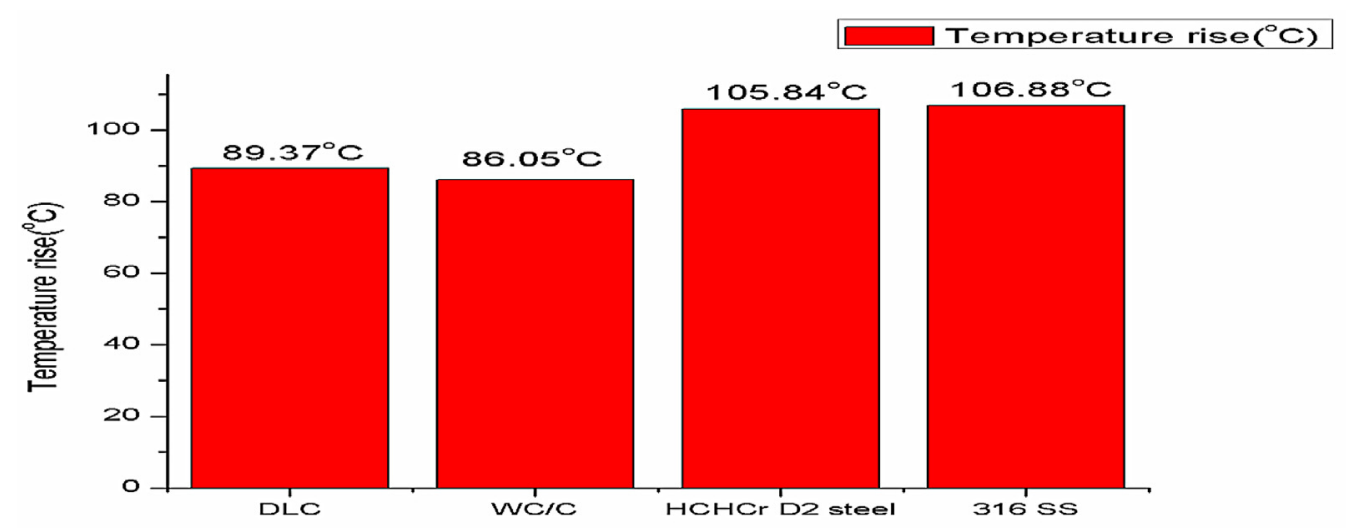

Fig. 9. Face temperature rise for DLC coated, WC/C coated, HCHCr D2 steel and 316 SS seal.

evaluation of life time and wear rate of $\mathrm{WC} / \mathrm{C}$ and $\mathrm{DLC}$ coated seal under various loading and lubricating condition is the aim of our future progress.

Acknowledgements. Authors wish to thank All India Council for Technical Education (AICTE) INDIA, for their financial support to execute this project work through Research Promotion Scheme. The authors are grateful to the Oerlikon Balzers Coating India Limited for providing the deposition of PVD DLC and WC/C film on HCHCr steel substrate.

\section{References}

[1] S. Kavinprasad, S. Shankar, M. Karthic, Experimental and CFD Investigations of Mechanical Seals under Dry/Compressed Air/Liquid Lubricating Conditions, Proc. Eng. 64 (2013) 419-425

[2] S. Kavinprasad, S. Shankar, M. Karthic, Experimental and CFD investigations of carbon/SS316 mechanical face seals under different lubricating conditions, Ind. Lubr. Tribol. 67 (2015) 124-132

[3] S. Shankar, P. Krishna kumar, G. Praveenkumar, Experimental study on frictional characteristics of tungsten carbide versus carbon as mechanical seals under dry and eco-friendly lubrications, Int. J. Refract. Metals Hard Mater. (2015)

[4] S. Shankar, G. Praveenkumar, P.K. Kumar, Frictional study of alumina, 316 stainless steel, phosphor bronze versus carbon as mechanical seals under dry sliding conformal contact, Proc. Institut. Mech. Eng., Part J: J. Eng. Tribol. (2015) 1350650115577116

[5] M. Sebastiani, et al., Wear mechanisms and in-service surface modifications of a Stellite $6 \mathrm{~B} \mathrm{Co}-\mathrm{Cr}$ alloy, Wear 290 (2012) 10-17

[6] B. Ben Difallah, et al., Microstructure, friction and wear analysis of thermoplastic based composites with solid lubricant, Mech. Ind. 13 (2012) 337-346

[7] E. Ciulli, Tribology research trends in Italy, Proc. Instit. Mech. Eng. Part J: J. Eng. Tribol. 223 (2009) 1091-1113

[8] A. Kovalchenko, et al., Development of ultrananocrystalline diamond (UNCD) coatings for multipurpose mechanical pump seals, Wear 270 (2011) 325-331

[9] I. Etsion, G. Halperin, A laser surface textured hydrostatic mechanical seal, Tribol. Trans. 45 (2002) 430-434

[10] T. Hu, Y. Zhang, L. Hu, Tribological investigation of $\mathrm{MoS}_{2}$ coatings deposited on the laser textured surface, Wear 278 (2012) 77-82

[11] A. Kovalchenko, et al., The effect of laser surface texturing on transitions in lubrication regimes during unidirectional sliding contact, Tribol. Int. 38 (2005) 219-225 
[12] N. Tala-Ighil, M. Fillon, Surface texturing effect comparative analysis in the hydrodynamic journal bearings, Mech. Ind. 16 (2015) 302

[13] A. Charitopoulos, et al., Thermohydrodynamic analysis of a textured sector-pad thrust bearing: effects on mechanical deformations, Mech. Ind. 15 (2014) 403-411

[14] F. Mubarok, et al., Enhanced sealing performance with CVD nanocrystalline diamond films in self-mated mechanical seals, Diamond and Relat. Mater. 17 (2008) $1132-1136$

[15] A. Sumant, et al., Ultrananocrystalline diamond film as a wear-resistant and protective coating for mechanical seal application, Tribol. Trans. 48 (2005) 24-31

[16] K. Yamamoto, K. Matsukado, Effect of hydrogenated DLC coating hardness on the tribological properties under water lubrication, Tribol. Int. 39 (2006) 1609-1614

[17] A. Semenov, Tribological properties and vacuum ionplasma methods of application of diamond and diamondlike coatings, J. Frict. Wear 30 (2009) 62-75

[18] A. Grill, Tribology of diamondlike carbon and related materials: an updated review, Surf. Coat. Technol. 94-95 (1997) 507-513

[19] J. Mo, M. Zhu, Tribological investigation of WC/C coating under dry sliding conditions, Wear 271 (2011) 19982005

[20] E. Vera, et al., A study of the wear performance of TiN, $\mathrm{CrN}$ and WC/C coatings on different steel substrates, Wear 271 (2011) 2116-2124
[21] X. Yu, S. He, R. Cai, Frictional characteristics of mechanical seals with a laser-textured seal face, J. Mater. Proc. Technol. 129 (2002) 463-466

[22] S.K. Choudhary, R. Jadoun, International journal of engineering sciences \& research technology current research issue, trend and applications of powder mixed dielectric electric discharge machining (PM-EDM): A Review.

[23] G. Jones, On the tribological behaviour of mechanical seal face materials in dry line contact: Part I. Mechanical carbon, Wear 256 (2004) 415-432

[24] O. Wänstrand, M. Larsson, P. Hedenqvist, Mechanical and tribological evaluation of PVD WC/C coatings, Surf. Coat. Technol. 111 (1999) 247-254

[25] H. Engqvist, et al., Tribofilm formation on cemented carbides in dry sliding conformal contact, Wear 239 (2000) 219-228

[26] M. Chowdhury, et al., The effect of sliding speed and normal load on friction and wear property of aluminum, Int. J. Mech. Mechatron. Eng. 11 (2011) 53-57

[27] Y. Xiao, et al., The tribological performance of TiN, $\mathrm{WC} / \mathrm{C}$ and DLC coatings measured by the four-ball test, Ceramics Int. 40 (2014) 6919-6925

[28] K.C. Ludema, Friction, wear, lubrication: a textbook in tribology, CRC press, 1996

[29] B. Bhushan, Modern Tribology Handbook, Two Volume Set, CRC Press, 2010 